\title{
PENGARUH SOLUTION HEAT TREATMENT TERHADAP SIFAT FISIS DAN MEKANIK PROSES PENGELASAN FSSW AA6063-T5
}

\author{
Ciptadi Natawiguna ${ }^{1}$, Nurul Muhayat ${ }^{1}$, Teguh Triyono ${ }^{1}$ \\ ${ }^{1}$ Program Studi Teknik Mesin - Universitas Sebelas Maret \\ e-mail addresses : ciptadinatawiguna.10@gmail.com
}

Keywords : Abstact:

FSSW, AA6063-T5, solution heat treatment, precipitation.

\begin{abstract}
Friction stir spot welding (FSSW) of aluminum alloy AA6063-T5 will decrease the strength and hardness. Physical and mechanical properties of aluminum alloy can be improved by heat treatment. Heat treatment is affected by temperature and holding time. The heat treatment process used for this research was solution heat treatment with temperature variation 470, 500, $530^{\circ} \mathrm{C}$ and holding time 1 and 2 hours. The tests included microstructure test, tensile shear test and vickers hardness test. Result of the research, it was found that $\mathrm{Mg}_{2} \mathrm{Si}$ particles were precipitated from the grain boundaries part into the aluminum matrix with the coarser size and the distance was increasing as the temperature and the holding time increases. The highest shear tensile strength of 3735,2 N was obtained from the temperature variation of $470{ }^{\circ} \mathrm{C}$ and the holding time of 1 hour. The lowest tensile shear strength of 3172,6 $N$ was obtained from temperature variation of $530^{\circ} \mathrm{C}$ and 2 hours of holding time. The highest hardness value was obtained of $470^{\circ} \mathrm{C}$ variation and 1 hour was 43,7 HVNand the lowest hardness value at $530^{\circ} \mathrm{C}$ variation and 2 hours of holding time was 30,1 HVN.
\end{abstract}

\section{PENDAHULUAN}

Aluminium dan paduannya merupakan logam yang banyak digunakan di bidang teknik karena mempunyai berbagai keunggulan antara lain ringan, mempunyai sifat mampu bentuk (formability) yang baik, kekuatan tarik relatif tinggi, tahan korosi. Sifat mekanik dari alumunium paduan dapat ditingkatkan dengan pengerjaan dingin atau perlakuan panas, serta mempunyai sifat mampu las (weldability) yang bervariasi tergantung pada jenis paduannya. Berbagai kelebihan di atas menyebabkan aluminium dan paduannya banyak digunakan di bidang struktur dan pemesinan, seperti pesawat terbang, kapal, kendaraan serta industri otomotif.

Pengelasan merupakan bagian yang penting dalam suatu proses industri, dan kebutuhan akan pengelasan sangat tinggi oleh karena itu teknologi pengelasan semakin lama semakin berkembang. Penggunaan teknologi las biasanya dipakai dalam bidang konstruksi, otomotif, perkapalan, pesawat terbang, dan bidang lainnya yang dalam beberapa tahun terakhir ini mengembangkan teknologi material ringan seperti alumunium alloy.

Baru-baru ini, varian dari FSW disebut Friction Stir Spot Welding (FSSW) telah dikembangkan dan diimplementasikan dalam industri otomotif sebagai pengganti resistance spot welding untuk aluminium. Pada dasarnya, sistem kerja FSSW sama dengan FSW, yang membedakan adalah gerakan dalam proses eksekusi. Pada FSW, tool bergerak sepanjang bagian yang dilas, sedangkan FSSW terfokus pada sambungan satu titik yang disebut sebagai sambungan titik (spot). Selama proses FSSW, pin mengalami kontak langsung dengan benda kerja untuk waktu yang lebih lama. Akibatnya, gaya gesekan antara pin dan benda kerja menghasilkan sebagian besar energi panas. Karakteristik ini membuat proses FSSW berbeda dari proses FSW (Awang, 2007).

Namun demikian las FSSW mempunyai kelemahan dalam mengelas material alumunium paduan khususnya AA6063, yaitu pada daerah HAZ (Heat Affected Zone), TMAZ (Thermomechanically Affected Zone) dan daerah las (nugget) sepanjang garis sambungan benda kerja, mengalami pelunakan akibat rekristalisasi saat proses stirring, sehingga kekerasan dan kekuatan tarik menurun. Untuk meningkatkan kekerasan dan kekuatan tarik daerah lasan tersebut, benda las perlu mendapat perlakuan panas kembali dengan proses precipitation hardening. Proses precipitation hardening tersebut dapat dilakukan dengan beberapa rangkaian dan merupakan rangkaian heat treatment yang kedua, dimana sebelum melakukan precipitation hardening benda las harus diperlakukan solution heat treatment terlebih dahulu.

Solution heat treatment merupakan proses perlakuan panas ulang (reheating) dan pendinginan yang terkontrol yang dilakukan pada hasil pengelasan suatu komponen, dengan tujuan 
mengubah sifat fisis dan sifat mekanis dari suatu bahan atau logam sesuai dengan yang diinginkan (Kamenichny, 1969). Penelitian ini akan membahas tentang pengaruh solution heat treatment terhadap sifat fisik dan mekanik proses pengelasan FSSW dengan material AA6063-T5 serta fenomena yang terjadi ketika proses solution heat treatment berlangsung.

\section{METODOLOGI PENELITIAN \\ Bahan}

Plat alumunium yang digunakan untuk mengelas FSSW. Plat AA6063-T5 berdimensi 100 x 25 x 3 mm yang akan dilas FSSW dengan sambungan lap joint.

\section{Proses Persiapan}

Pembuatan spesimen yang digunakan dalam penelitian ini yaitu dengan pengelasan friction stir spot welding (FSSW). Pengelasan dilakukan menggunakan mesin milling yang dimodifikasi dibagian tool nya. Parameter yang dipakai untuk pembuatan spesimen las yaitu kecepatan putar 1600 rpm, diameter shoulder $12 \mathrm{~mm}$, diameter pin $7 \mathrm{~mm}$, plunge depth $4 \mathrm{~mm}$ dan dwell time $5 \mathrm{~s}$. Kemudian spesimen las tersebut diperlakukan solution heat treatment menggunakan mesin furnace dengan variasi suhu sebesar $470,500,530^{\circ} \mathrm{C}$ dan ditahan dengan lama waktu holding time 1 dan 2 jam, kemudian didinginkan cepat (quenching) mengggunakan air.

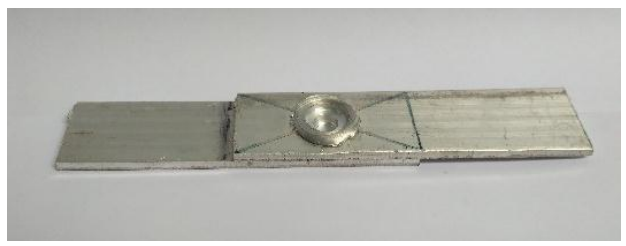

Gambar 1 Spesimen hasil pengelasan FSSW

\section{Pengujian}

Pengujian yang dilakukan adalah uji kekerasan, tarik geser dan foto mikrostruktur.

\section{a. Uji keras}

Uji keras bertujuan untuk mengetahui ketahanan suatu material terhadap deformasi plastis pada daerah lokal dan permukaan material. Pengujian ini menggunakan alat uji keras micro hardness vickers dengan mengunakan ASTM E384. Uji keras Vickers sering disebut Diamond Pyramid Hardness Test yaitu dengan menggunakan indentor berbentuk piramida yang saling berhadapan membentuk sudut $136^{\circ}$. Angka kekerasan vickers didefinisikan sebagai beban dibagi luas permukaan lekukan. Pada prakteknya, luas ini dihitung dari pengukuran mikroskopik panjang diagonal jejak.

\section{b. Uji kekuatan tarik geser}

Uji kekuatan tarik geser adalah salah satu uji stress-strain mekanik yang bertujuan untuk mengetahui kekuatan suatu bahan dengan cara memberikan beban gaya yang berlawanan arah dalam satu garis lurus. Pengujian ini menggunakan alat uji UTM (Universal Testing Machine) dengan mengunakan ASTM E8/E8M.

\section{c. Uji mikrostruktur}

Pengujian mikrostruktur bertujuan untuk mengetahui perubahan bentuk struktur mikro dan persebaran endapan partikel (presipitat) yang terjadi pada spesimen uji dan pengaruhnya terhadap kekerasan dan kekuatan tarik.

\section{HASIL DAN PEMBAHASAN}

\section{Hasil pengujian mikrostruktur}

Observasi mikroskopik dilakukan sesuai dengan pemetaan daerah seperti pada Gambar 2. Observasi mikroskopik menunjukan struktur mikro pada hasil sambungan bahwa pada tiap daerah yang diamati (BM, HAZ, TMAZ, dan SZ) terdapat karakteristik perbedaan daerah yang sama.

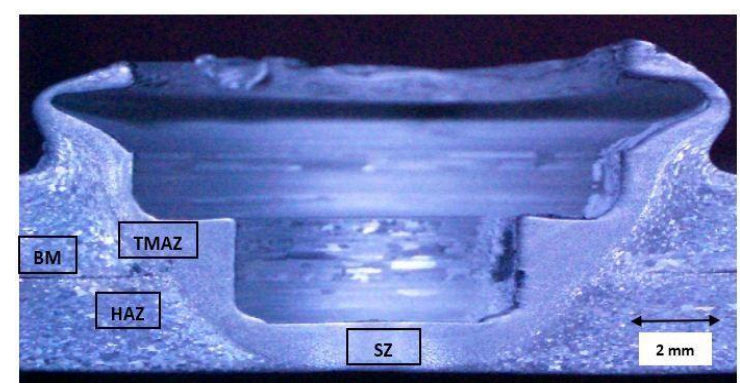

Gambar 2 Foto pemetaan daerah pengelasan FSSW

Hasil observasi mikroskopik pada daerah HAZ untuk setiap variasi ditunjukan pada Tabel 1. Pada daerah HAZ yang telah di solution heat treatment partikel $\mathrm{Mg}_{2}$ Si mengalami presipitasi, sehingga letak partikel $\mathrm{Mg}_{2} \mathrm{Si}$ yang berasal dari sekeliling batas butir berpindah/mengalami endapan ke dalam butiran $\alpha$. Kemudian dengan pendinginan cepat menggunakan quenching mengakibatkan partikel $\mathrm{Mg}_{2} \mathrm{Si}$ tersebut akan mempertahankan bentuknya pada fasa tunggal.

Proses pendinginan dilakukan di dalam media cair yang bertujuan untuk mempertahankan larutan padat yang terbentuk selama proses solution heat treatment. Media pendingin yang digunakan pada proses ini yaitu air dengan temperatur $28{ }^{\circ} \mathrm{C}$. Pendinginan ini juga berfungsi untuk mempertahankan jumlah tempat atom kosong yang dibutuhkan selama proses pembentukan endapan. Pengaruh dari menambah besarnya suhu solution treatment maka ukuran butir di daerah HAZ akan tampak bertambah besar, begitu pula dengan seiring bertambahnya waktu heat treatment nya (holding time). Pada Tabel 1 menunjukkan bahwa ukuran butir pada daerah HAZ yang paling besar terbentuk pada variasi spesimen $\mathrm{C} 2$ (suhu solution heat treatment $530^{\circ} \mathrm{C}$ dan holding time 2 jam). 
Mekanika: majalah ilmiah mekanika Volume 17 Nomor 1 Maret 2018

Tabel 1 Observasi mikroskopik daerah HAZ

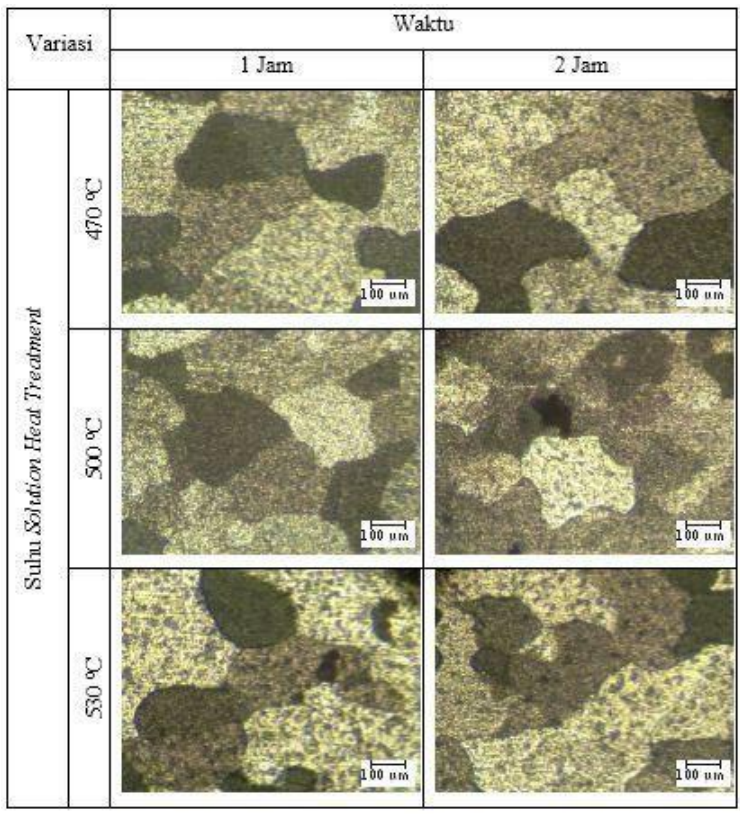

Tabel 2 Observasi mikroskopik daerah TMAZ

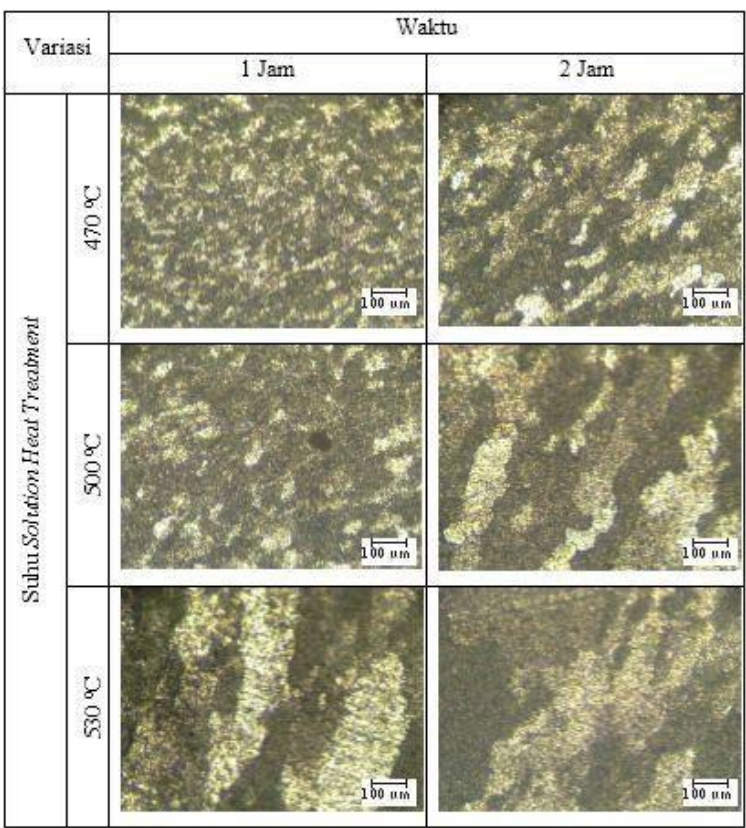

Hasil observasi mikroskopik TMAZ dapat dilihat pada Tabel 2. Bagian TMAZ ditunjukan dengan ukuran butiran alumunium alloy yang lebih kecil dibandingkan ukuran butiran pada HAZ. TMAZ merupakan daerah yang terkena panas serta deformasi plastis akibat desakan dari tool pada material selama proses penyambungan. Karakteristik TMAZ dapat dilihat dari arah orientasi butir yang seragam karena terbentuk menyesuaikan arah adukan material. Terlihat pada Tabel 2 bahwa variasi spesimen A1 memiliki ukuran butir yang paling kecil dibandingkan dengan variasi yang lainnya. Hal ini disebabkan oleh suhu solution heat treatment yang diperlakukan pada spesimen A1 adalah suhu dengan variasi yang paling rendah yaitu $470{ }^{\circ} \mathrm{C}$ dan holding time 1 jam. Sedangkan ukuran butir paling besar pada daerah TMAZ didapat dari variasi spesimen $\mathrm{C} 2$. Hal ini disebabkan oleh suhu solution heat treatment yang diperlakukan pada spesimen $\mathrm{C} 2$ adalah suhu dengan variasi yang paling tinggi yaitu $530{ }^{\circ} \mathrm{C}$ dan holding time 2 jam.

Tabel 3 Observasi mikroskopik daerah SZ

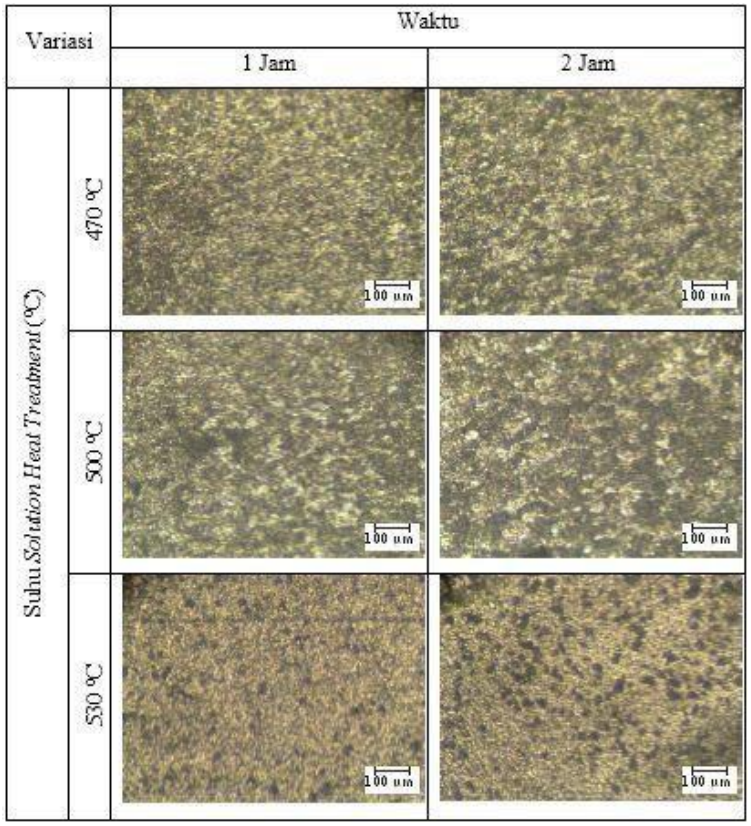

Data observasi mikroskopik pada SZ (stir zone) ditunjukan pada Tabel 3. Butir yang terdapat pada SZ memiliki ukuran butir yang paling kecil dibandingkan dengan daerah lainnya.

\section{Hasil pengujian tarik geser}

Pengujian tarik geser dilakukan untuk mengetahui sifat mekanik dari hasil pengelasan dengan pembebanan maksimum. Beban yang diberikan pada sambungan las merupakan beban statis dengan beban sebesar $20 \mathrm{kN}$ dan dengan kecepatan penarikan $5 \mathrm{~mm} / \mathrm{min}$. Hasil dari pengujian tarik geser pada sambungan las FSSW setelah proses solution heat treatment ditunjukan pada Gambar 3.

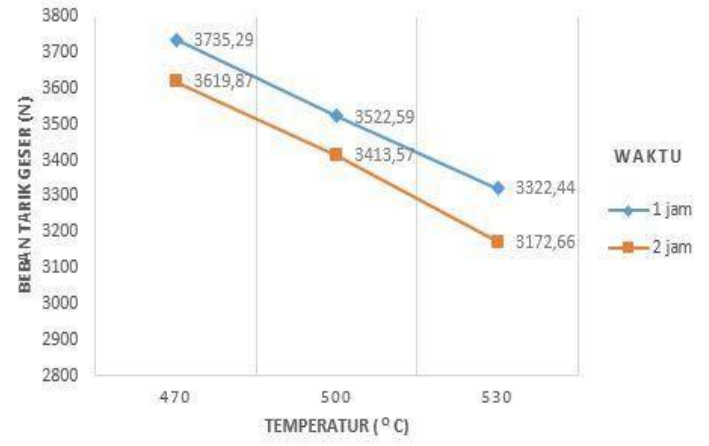

Gambar 3 Grafik hasil pengujian tarik geser 
Berdasarkan grafik nilai hasil pembebanan uji tarik geser diatas didapatkan trend yang berbeda untuk setiap variasi. Variasi spesimen A1 (suhu solution heat treatment $470^{\circ} \mathrm{C}$ dan holding time 1 jam) memiliki nilai pembebanan tarik geser yang lebih besar besar daripada variasi spesimen yang lainnya. Variasi spesimen A1 memiliki nilai pembebanan tarik geser tertinggi yaitu 3735,2 N. Variasi spesimen B1 (suhu solution heat treatment $500^{\circ} \mathrm{C}$ dan holding time 1 jam) menghasilkan trend yang turun yaitu 3522,59 $\mathrm{N}$, begitupun juga dengan variasi spesimen $\mathrm{C} 1$ (suhu solution heat treatment $530^{\circ} \mathrm{C}$ dan holding time 1 jam).

Variasi spesimen A2 (suhu solution heat treatment $470^{\circ} \mathrm{C}$ dan holding time 2 jam) memiliki nilai pembebanan tarik geser yang lebih besar dibanding variasi spesimen B2 (suhu solution heat treatment $500^{\circ} \mathrm{C}$ dan holding time 2 jam), dan nilai pembebanan tarik geser variasi spesimen $\mathrm{C} 2$ (suhu solution heat treatment $530^{\circ} \mathrm{C}$ dan holding time 2 jam) menunjukkan hasil nilai beban uji tarik terendah diantara variasi-variasi lainnya yaitu 3172,6 N. Hal ini didukung dengan penelitian Totik yang menyatakan bahwa nilai regangan akan naik dan tegangan tarik akan turun seiring dengan pertambahan suhu homogenisasi (Totik, 2003). Selain itu juga disebabkan oleh meluasnya hook yang merambat keatas sampai dengan daerah nugget pada benda las yang diakibatkan oleh retakan panas (hot cracking) dari proses solution heat treatment dengan suhu 530 ${ }^{\circ} \mathrm{C}$ dan holding time 2 jam kemudian didinginkan secara cepat (quenching) dengan air seperti yang ditunjukkan pada Gambar 4. Sebagai perbandingan, spesimen BSHT (before solution heat treatment) atau spesimen yang telah dilas FSSW dan sebelum diberi perlakukan solution heat treatment menghasilkan nilai beban uji tarik geser yang lebih tinggi daripada spesimen yang sudah diberi perlakukan solution heat treatment, yaitu sebesar 4660,1 N.

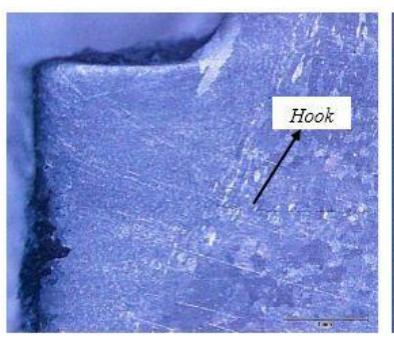

(a)

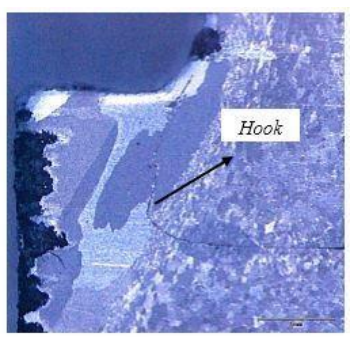

(b)
Gambar 4 (a) Hook pada spesimen BSHT, (b) Hook spesimen $\mathrm{C} 2$ (suhu $530^{\circ} \mathrm{C}$; waktu 2 jam) yang merambat akibat retakan panas.

Mode patahan yang terjadi pada tiap variasi membuktikan hubungan antara nilai tensile shear load dengan nilai kekerasan vickers dan juga besarnya daerah stir zone. Dapat dilihat pada Tabel 4 bahwa pada semua variasi A1, A2, B1, B2, C1 dan C2 mengalami mode patahan pullout dimana pada daerah sekitar sambungan mengalami pembengkokan terlebih dahulu sebelum patah. Hasil yang didapatkan bahwa pengaruh dari nilai tensile shear load dan nilai kekerasan vickers yang lebih baik serta luas sambungan yang lebih besar akan menghasilkan mode patahan pullout. Patahan pullout mampu menahan gaya yang lebih baik pada pengujian tarik geser dibandingkan dengan sambungan yang memiliki mode patahan interface (Zhang, 2011).

Tabel 4 Mode patahan tampak samping hasil uji tarik geser

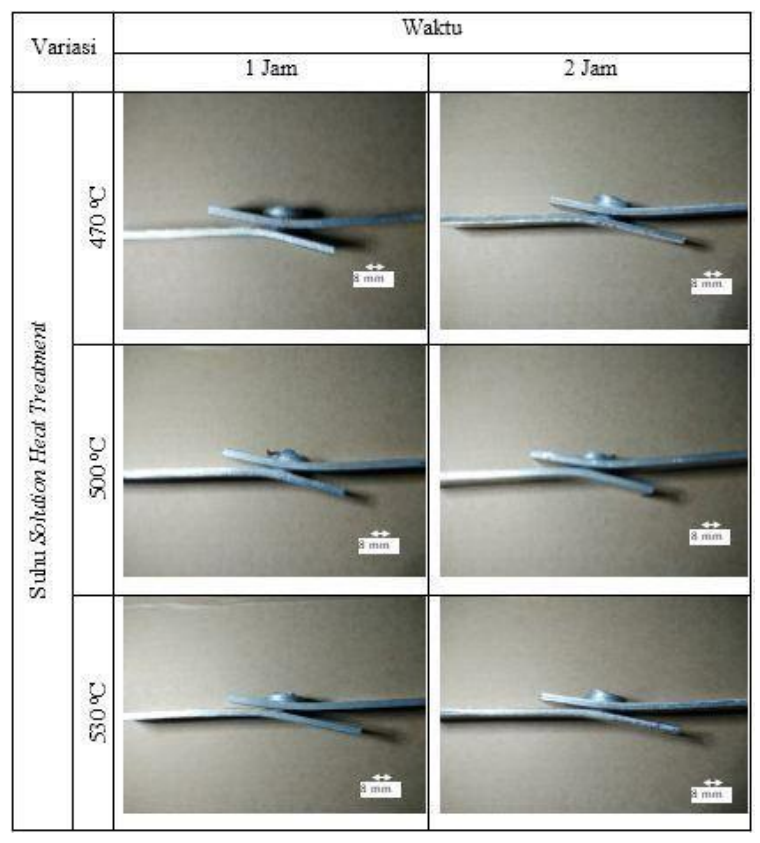

\section{Hasil uji keras vickers}

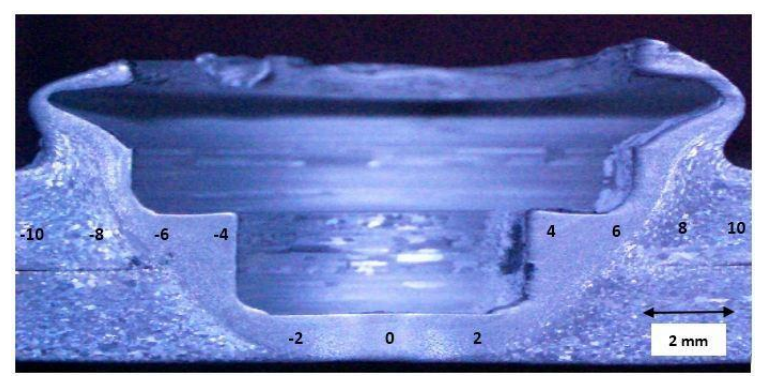

Gambar 5 Titik pengambilan data uji keras Micro Vickers

Hasil pengujian kekerasan micro vickers menunjukan adanya trend yang hampir sama pada setiap spesimen, nilai kekerasan sambungan tertinggi diperoleh pada lokasi stir zone atau biasa disebut nugget. Namun masih terdapat sedikit perbedaan pada persebaran kekerasan pada penelitian ini. Sebagai perbandingan nilai hasil uji kekerasan tertinggi yang dihasilkan dari spesimen BSHT (Before Soloution Heat Treatment) yaitu 53,3 HV yang didapat pada nugget tepatnya di daerah sekeliling keyhole. Kemudian nilai kekerasan tertinggi ditunjukkan oleh variasi A1 (suhu solution heat treatment $470^{\circ} \mathrm{C}$ dan holding time 1 jam) dengan nilai kekerasan 43,7 HV terdapat pada sisi tepi stir zone atau tepatnya 
didapatkan pada nugget tepatnya di daerah sekeliling keyhole yaitu pada titik nomer 2 dan -2 dari skema gambar lokasi pengambilan data uji keras vickers seperti yang ditunjukkan pada Gambar 5.

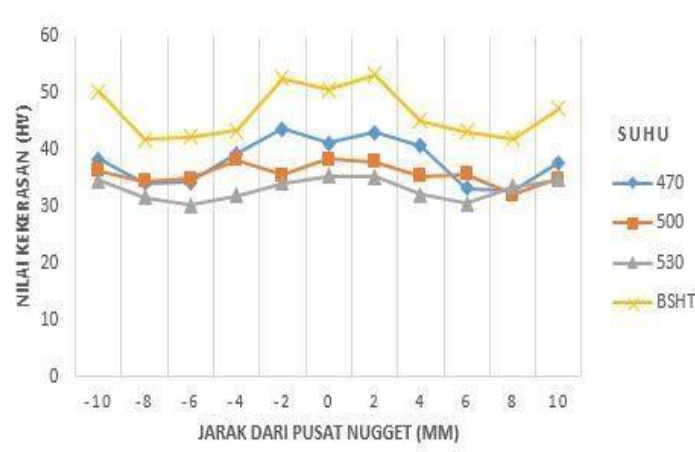

Gambar 6 Grafik hasil uji Micro Vickers dengan suhu solution heat treatment selama 1 jam pada suhu 470 , $500,530^{\circ} \mathrm{C}$ dan BSHT.

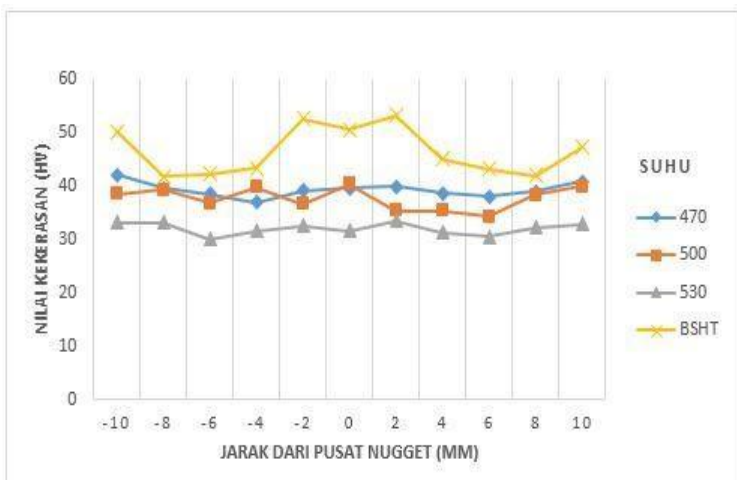

Gambar 7 Grafik hasil uji Micro Vickers dengan suhu solution heat treatment selama 2 jam pada suhu 470 , $500,530^{\circ} \mathrm{C}$ dan BSHT.

Center of nugget merupakan daerah dengan nilai kekerasan tinggi karena memiliki temperatur tertinggi pada proses pengelasan FSSW. Hal ini didukung oleh penelitian Elangovan dkk (2008) yang mendapatkan nilai kekerasan tertinggi berada pada center of nugget pada AA6061. Daerah center of nugget ini mengalami perubahan deformasi plastis yang hebat akibat desakan pin dan putaran tool pada permukaan benda kerja. Hal ini mengakibatkan mengecilnya ukuran butir yang dihasilkan. Dengan semakin mengecilnya ukuran butir yang dihasilkan maka ikatan antar butir yang terbentuk akan semakin banyak. Pernyataan ini didukung oleh penelitian Chi-Sung dkk (2012) yang menyatakan bahwa ukuran butir di bawah pin disebabkan oleh deformasi akibat torsi bertekanan tinggi disertai dengan peningkatan temperatur. Hal inilah yang menyebabkan nilai kekerasan tertinggi berada pada center of nugget sambungan las FSSW. Sedangkan nilai kekerasan terendah didapatkan dari variasi $\mathrm{C} 2$ (suhu solution heat treatment $530^{\circ} \mathrm{C}$ dan holding time 2 jam) dengan nilai kekerasan 30,1
HV terdapat pada daerah HAZ atau tepatnya pada titik nomer 8 dari skema gambar lokasi pengambilan data uji keras vickers seperti yang ditunjukkan pada Gambar 5. Berkurangnya nilai kekerasan pada daerah HAZ dan TMAZ dari material dapat diakibatkan oleh menghilangnya efek strain hardening yang merupakan hardening treatment pada awal proses penguatan material dengan cara cold work rolling. Efek cold work rolling hilang dikarenakan tercapainya temperatur rekristalisasi dari material yang disebabkan oleh proses pengelasan akibat desakan tool terhadap material yang meningkatkan temperatur sehingga efek dislocation density pada batas butir menghilang dan mengakibatkan kekuatan ikatan antar butir berkurang. Dislocation density adalah jumlah banyaknya dislokasi yang terjadi pada luasan material. Karena dislokasi berbentuk garis, maka dirumuskan menjadi panjang total garis dislokasi per volume material. Tujuan dari work hardening adalah menguatkan material dengan cara memberikan deformasi plastis pada temperatur yang jauh lebih rendah dari melting point sehingga nilai dislocation density akan bertambah (Shoba, 2015).

Dari grafik hasil uji keras vickers yang ditunjukkan pada Gambar 6 dan 7 dapat dilihat bahwa terjadi penurunan nilai kekerasan berturut-turut dari variasi A1 ke C2. Semakin menurunnya nilai kekerasan dari variasi spesimen ini dipengaruhi oleh suhu solution heat treatment dan waktu holding time. Semakin besar suhu solution heat treatment dan semakin lama waktu pemanasan mengakibatkan endapan partikel $\mathrm{Mg}_{2} \mathrm{Si}$ menjadi tersebar pada jarak yang agak berjauhan, serta akan membuat ukuran endapan partikel tersebut membesar seperti yang terlihat pada Tabel 1,2 dan 3. Terjadinya hal tersebut akan mengakibatkan nilai kekuatan dan kekerasan material akan menjadi berkurang. Hal ini seperti yang diungkapkan oleh Sinaga (1998) bahwasanya temperatur pemanasan yang terlalu tinggi atau waktu pemanasan yang terlalu lama akan mengakibatkan terjadinya penurunan kekuatan atau kekerasan material. Kekuatan dan kekerasan sangat dipengaruhi oleh morfologi endapan partikel yang terjadi. Dalam proses solution heat treatment ini terjadi endapan partikel yang besar dan tersebar pada jarak yang sangat jarang, maka dislokasi sangat mudah bergerak, sehingga kekuatan materialnya akan menjadi sangat rendah.

\section{KESIMPULAN}

Beberapa kesimpulan yang dapat diperoleh dari penelitian yang telah dilakukan adalah sebagai berikut:

1. Ukuran butir pada daerah SZ, HAZ, TMAZ membesar seiring dengan bertambahnya suhu solution heat treatment dan lama waktu dwell time.

2. Seiring dengan bertambahnya suhu solution heat treatment dan lama waktu dwell time maka 
kekuatan tarik geser dari benda las akan semakin berkurang. Nilai pembebanan uji tarik geser tertinggi terjadi pada spesimen A1 (suhu solution heat treatment $470^{\circ} \mathrm{C}$ dan holding time 1 jam) yaitu sebesar $3735,2 \mathrm{~N}$, sedangkan nilai pembebanan uji tarik geser terendah terjadi pada spesimen $\mathrm{C} 2$ (suhu solution heat treatment $530^{\circ} \mathrm{C}$ dan holding time 2 jam) yaitu sebesar $3172,6 \mathrm{~N}$.

3. Seiring dengan bertambahnya suhu solution heat treatment dan lama waktu dwell time maka nilai kekerasan dari benda las akan semakin berkurang. Nilai kekerasan tertinggi terjadipada spesimen A1 (suhu solution heat treatment $470^{\circ} \mathrm{C}$ dan holding time 1 jam) yaitu sebesar 43,7 HVN, sedangkan nilai kekerasan terendah terjadi pada spesimen $\mathrm{C} 2$ (suhu solution heat treatment $530^{\circ} \mathrm{C}$ dan holding time 2 jam) yaitu $30,1 \mathrm{HVN}$.

\section{DAFTAR PUSTAKA}

[1] J. Chi-Sung, Al. et, "Material properties of friction stir spot welded joints of dissimilar aluminum alloys," Transactions of Nonferrous Metals Society of China, vol. 22, pp. s605-s613, 2012.

[2] K. Elangovan, K. dan V. Balasubramanian, "Influences of tool pin profile and tool shoulder diameter on the formation of friction stir processing zone in AA6061 aluminium alloy," Materials \& design, vol. 29, no. 2, pp. 362-373, 2008.

[3] I. Kamenichny, "Short Handbook of Heat Treatment," Moscow Peace Publishers, 1969.

[4] Mokhtar Awang, "Simulation of Friction Stir Spot Welding (FSSW) Process: Study of Friction Phenomena," Department of Mechanical and Aerospace Engineering Morgantown, West Virginia, 2007.

[5] R. Sinaga, "Meningkatkan sifat mekanik bahan aluminium paduan (Al-Mg-Si)," Prosiding pertemuan ilmiah sains materi III, Serpong, 1998.

[6] C. Shoba, al. et, "Influence of dislocation density on the residual stresses induced while machining Al/SiC/RHA hybrid composites," J. of Mater. Research and Tech., vol. 4, no. 3, pp. 273-277, 2015.

[7] Y. Totik, "The effect of homogenisation treatment on cold deformations of AA 2014 and AA 6063 alloys," Mechanical Engineering Department, Faculty of Engineering, Atatürk University, vol. 147, pp 60-64, Erzurum, Turkey, 2003.

[8] Zhaohua Zhang, "Effect of welding parameters on microstructure and mechanical propertiesof friction stir spot welded 5052 aluminum alloy," Materials and Design, vol. 32, pp. 4461-4470, 2011. 